\title{
Studies on the Clinical Significance of Nonesterified and Total Cholesterol in Urine
}

\author{
D. Jüngst ${ }^{1}$, J. Wallner ${ }^{1}$, A. Pickel ${ }^{1}$, A. Stadler ${ }^{1}$, W. Eiermann ${ }^{2}$, F.J. Marx ${ }^{3}$, and H.J. Karl ${ }^{1}$ \\ ${ }^{1}$ Medizinische Klinik II (Direktor: Prof. Dr. G. Paumgartner) \\ ${ }^{2}$ Frauenklinik (Direktor: Prof. Dr. K. Richter) \\ ${ }^{3}$ Urologische Klinik (Direktor: Prof. Dr. E. Schmiedt) Klinikum Großhadern der Universität München
}

Summary. Gas-liquid chromatographic determinations of nonesterified and total urinary cholesterol were performed in 137 normals, 264 patients with various internal diseases without evidence of neoplasias or diseases of the kidney or urinary tract, 497 patients with malignancies and 236 patients with diseases of the kidney, urinary tract infections or prostatic adenoma with residual urine. A normal range (mean \pm $2 \mathrm{SD}$ ) of $0.2-2.2 \mathrm{mg} / 24$ hours nonesterified cholesterol (NEC) and of $0.3-3.0 \mathrm{mg} / 24$ hours total cholesterol (TC) was calculated.

Values of urinary cholesterol excretion were independent of age and sex and did not correlate with cholesterol levels in plasma. Patients with various internal diseases, without evidence of neoplasias nor diseases of the kidney or obstruction of the urinary tract, showed normal urinary cholesterol excretions, as did patients with infections of the urinary tract.

However, elevated urinary cholesterol was found in patients with diseases of the kidney or urinary tract obstruction (prostatic adenoma with residual urine), malignant diseases of the urogenital tract and metastasing carcinoma of the breast. In patients with other malignant diseases urinary cholesterol was usually normal.

Lesions of the urothelial cell membranes are considered to be the most likely cause of urinary cholesterol hyperexcretion. The clinical value of urinary cholesterol determinations as a possible screening test for urogenital carcinomas in unselected populations is limited by lacking specificity, expensive methodology and low prevalence of the mentioned carcinomas, although elevated urinary cholesterol excretions have been observed in early clinical stages of urogenital cancers.

Key words: Urinary cholesterol - Diagnostic value - Diseases of the urogenital system

Offprint requests to: Dr. D. Jungst (address see page 552)
Untersuchungen zur klinischen Bedeutung des Freien und Gesamtcholesterins im Urin

Zusammenfassung. Gaschromatographische Bestimmungen von unverestertem und Gesamtcholesterin im Urin wurden bei 137 Normalpersonen, 264 Patienten mit verschiedenen internen Erkrankungen, ohne Hinweis für ein Malignom oder eine Erkrankung der Nieren und ableitenden Harnwege, 479 Patienten mit Malignomen und 236 Patienten mit Erkrankungen der Niere, Infektionen der ableitenden Harnwege oder Prostataadenom mit Restharn, durchgeführt.

Ein Normalbereich $(\bar{X} \quad \log \pm 2 \mathrm{SD})$ von 0.2 $2.2 \mathrm{mg} / 24$ Stunden für unverestertes Cholesterin und von $0.3-3.0 \mathrm{mg} / 24$ Stunden für Gesamtcholesterin wurde errechnet.

Die Ausscheidung des Cholesterins im Urin war unabhängig vom Alter und Geschlecht und korrelierte nicht mit den Cholesterinwerten im Plasma. Patienten mit verschiedenen internen Erkrankungen, ohne Hinweis für ein Malignom oder eine Erkrankung der Nieren und ableitenden Harnwege, zeigten eine normale Cholesterinausscheidung im Urin, wie auch $\mathrm{Pa}$ tienten mit Harnwegsinfektionen.

Dagegen wurden ein erhöhtes Urincholesterin bei Patienten mit Nierenerkrankungen oder Prostataadenomen mit Restharn, malignen Erkrankungen des Urogenitaltrakts, sowie bei metastasierenden Mammacarcinomen beobachtet.

Bei Patienten mit Malignomen anderer Lokalisation war die Cholesterinausscheidung im Urin gewöhnlich normal. Läsionen von Zellmembranen des Urothels können als die wahrscheinlichste Ursache einer gesteigerten Cholesterinausscheidung im Urin angesehen werden.

Der klinische Wert der Cholesterinbestimmung im Urin als möglicher Screeningtest für Urogenitalcarcinome in unselektierten Populationen ist begrenzt durch fehlende Spezifität, aufwendige Methodik und 
insbesondere die niedrige Prävalenz der erwähnten Carcinome, obwohl erhöhte Cholesterinausscheidungen im Urin auch in Frühstadien von Urogenitalcarcinomen beobachtet werden konnten.

Schlïsselwörter: Cholesterin im Urin - diagnostischer Wert - Erkrankungen des Urogenitalsystems

Anisotropic material is a well recognized component in the urine sediment of patients with the nephrotic syndrome (Bruger M, 1935; Zimmer JG et al., 1961, Klahr S et al., 1967). It has been pointed out that this microscopic material is apparently composed largely of cholesterol esters with a smaller proportion of free cholesterol (Zimmer JG et al., 1961). In addition to these findings there were some reports about increased urinary cholesterol in kidney diseases without nephrotic syndrome and various malignant diseases (Bloch E, Sobotka H, 1938; Sobotka H etal., 1939; Sobotka H et al., 1940; Trappe W, 1942; Bruger M, Ehrlich SB, 1943; Comings DE, 1963). Later studies demonstrated a lower incidence, about $10 \%$, of hypercholesteroluria in cancer (Burchell MM et al., 1949; Burchell MM, Maclagan NF, 1949). Using a more specific mass fragmentometric method hyperexcretion of urinary cholesterol had been observed in single patients with prostatic or bladder carcinomas (Frick J, Spiteller G, 1968; Spiteller G et al., 1971). At the same time, a specific gas-liquid chromatographic method was developed for the determination of nonesterified urinary cholesterol (Vela BA, Acevedo HF, 1969). They determined elevated values of this steroid in patients with carcinomas of steroid hormone producing glands and their main target tissues $(2,3,4,5,6)$. It was concluded that determinations of urinary cholesterol can be used as an additional biochemical test to detect these cancers.

Part of these results could be confirmed recently, demonstrating considerable diagnostic sensitivity of total urinary cholesterol determination in advanced prostatic cancer (Chu TM etal., 1975). However, as a result of gross deficiencies in patient selection, the clinical value of urinary cholesterol determinations is still not well defined.

Own previously published studies demonstrated considerable diagnostic sensitivity of nonesterified and especially total urinary cholesterol determination in prostatic cancer and papilloma or carcinoma of the bladder (Jüngst D et al., 1979a, b). Part of these results are included in the presented study which was carried out in an attempt to evaluate the clinical significance of nonesterified and total cholesterol determinations in urine with special regard to early stages of urogenital carcinomas.
In addition, urinary cholesterol measurements were performed in patients with nonmalignant diseases especially of kidney and urinary tract to investigate the diagnostic specificity of these parameters.

\section{Materials and Methods}

The study included a total of 1134 subjects. Normal range for nonesterified (NEC) and total urinary cholesterol (TC) was calculated using standard procedures and obtained from 137 clinically healthy, asymptomatic and biochemically normal individuals, 67 males and 70 females, covering an age range of 14 to 76 years.

The 264 patients with various internal diseases consisted of 75 with endocrine and metabolic, 68 with cardiovaseular, 78 with gastrointestinal, 27 with respiratory and 16 with haemopoetic disorders. The presence of neoplasias, kidney diseases and prostatic adenoma with residual urine had been excluded in this second control group with reasonable certainty.

A total of 497 patients with a diagnosis of cancer, based on cytological or histological examinations, were included in the study. Only were urinary samples with macroscopically blood contamination discarded, since the presence of occult blood in urine did not alter the determination of urinary cholesterol.

Patients with carcinomas of the prostate, bladder and kidney had been classified according to the TNM-system and were divided into two groups $\left(\mathrm{T}_{1} \mathrm{~N}_{0} \mathrm{M}_{0}-\mathrm{T}_{2} \mathrm{~N}_{0} \mathrm{M}_{0}\right.$ and $\mathrm{T}_{1} \mathrm{~N}_{1} \mathrm{M}_{0}-\mathrm{T}_{4} \mathrm{~N}_{4} \mathrm{M}_{1 \mathrm{~d}}$ ). Patients with carcinoma of the cervix and corpus uteri were classified due to the FIGO, patients with breast cancer were divided into stage I-II and stage III-IV according to the ICRP. In patients with cancer of other origin staging had not been possible in all cases, therefore, a division in different groups, due to the extension of the disease, had not been done.

236 patients revealed diseases of the kidney, urinary tract infections or prostatic adenomas with residual urine which were diagnosed by standard clinical procedures.

Glomerular diseases of the kidney were present in 12, tubular diseases in 24 and vascular diseases in 11.29 patients revealed an urolithiasis, 15 a renal cyst and 27 a nephrotic syndrome. Renal insufficiency of unknown etiology occurred in 29 patients, infections of the urinary tract in 32 and prostatic adenoma with residual urine in 57.

Nonesterified and total urinary cholesterol were analyzed in $2 \mathrm{ml}$ aliquots of $24 \mathrm{~h}$ urine with a gas-liquid chromatographic assay using 4-androstendione as internal standard and peakheight ratio technique for quantitation. This method has been described in detail previously (Jüngst et al. 1979 a).

\section{Results}

\section{Normal Subjects}

Based on the statistical analysis of the results, we obtained a mean excretion: $0.76 \mathrm{mg} / 24 \mathrm{~h} \mathrm{NEC}$ and $0.92 \mathrm{mg} / 24 \mathrm{~h} \mathrm{TC}$ in men and $0.84 \mathrm{mg} / 24 \mathrm{~h} \mathrm{NEC}$ and $0.98 \mathrm{mg} / 24 \mathrm{~h}$ TC in women. The range for normal values was calculated as the mean \pm 2 SD including $95 \%$ of the population. On the basis of these results, an upper normal limit: $2.2 \mathrm{mg} / 24 \mathrm{~h} \mathrm{NEC} \mathrm{and} 2.9 \mathrm{mg} /$ $24 \mathrm{~h} \mathrm{TC}$ was determined in men and $2.3 \mathrm{mg} / 24 \mathrm{~h} \mathrm{NEC}$ and $3.1 \mathrm{mg} / 24 \mathrm{~h} \mathrm{TC}$ in women. 


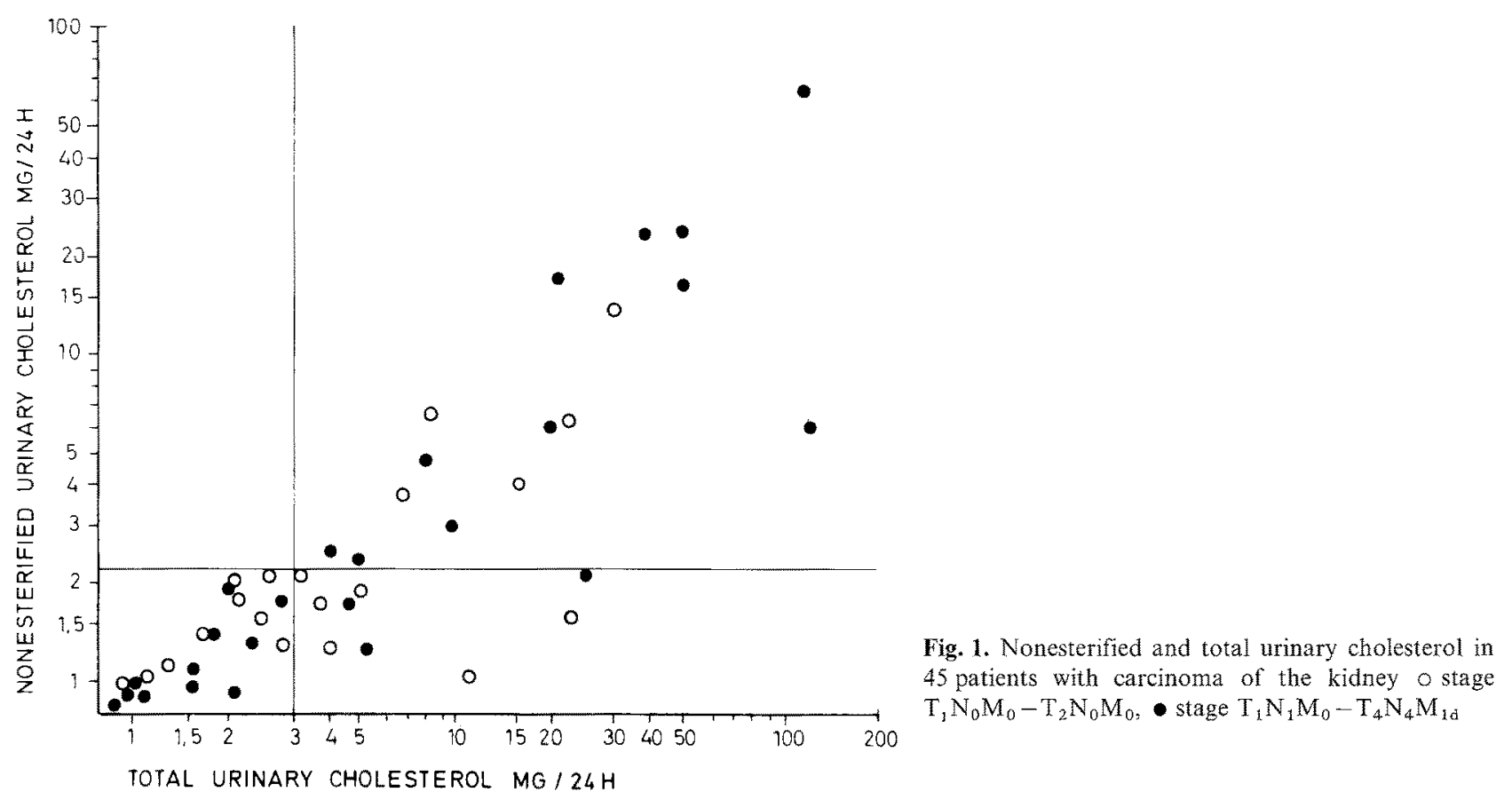

\section{Control Patients with Various Internal Diseases}

In 264 patients with various internal diseases urinary excretion of NEC and TC were within the normal range, except 3 cases with slightly elevated levels of NEC and one patient with elevated TC (NEC range $0.2-2.4$, median 0.7; TC range 0.3-3.1, median 1.0).

There was not a constant ratio between NEC and $\mathrm{TC}$; in most cases nonesterified cholesterol was the major component of total urinary cholesterol. No correlation between urinary cholesterol excretion and cholesterol concentrations in plasma was obtained, even in patients with marked hypercholesterolaemia urinary cholesterol values were normal.

\section{Carcinoma of the Prostate}

In prostatic carcinoma $\left(\mathrm{T}_{1} \mathrm{~N}_{0} \mathrm{M}_{0}-\mathrm{T}_{2} \mathrm{~N}_{0} \mathrm{M}_{0}\right)$ hyperexcretion of NEC was detected in 9 and of TC in 11 out of 24 patients (NEC range 0.4-24.2, median 1.2; TC range $0.5-51.4$, median 2.2). In advanced clinical stages of the disease $\left(\mathrm{T}_{3} \mathrm{~N}_{0} \mathrm{M}_{0}-\mathrm{T}_{4} \mathrm{~N}_{4} \mathrm{M}_{1 \mathrm{~d}}\right)$ elevated levels of NEC were measured in 25 and of TC in 27 out of 40 patients (NEC range 0.2-54.3; median 4.2; TC range 0.3-98.4, median 10.3).

\section{Papilloma and Carcinoma of the Bladder}

In papilloma and carcinoma of the bladder $\left(T_{1} N_{0} M_{0}-T_{2} N_{0} M_{0}\right)$ hyperexcretion of NEC occurred in 23 and of TC in 29 out of 44 patients (NEC range $0.2-68.4$, median 2.7 ; TC range $0.3-398.4$, median 7.0).
In 21 patients with carcinoma of the bladder $\left(\mathrm{T}_{3} \mathrm{~N}_{0} \mathrm{M}_{0}-\mathrm{T}_{4} \mathrm{~N}_{4} \mathrm{M}_{1 \mathrm{~d}}\right)$ elevated $\mathrm{NEC}$ was detected in 16 and elevated TC in 19 (NEC range $0.5-29.8$, median 7.8 ; TC range $0.6-96.5$, median 14.8 ).

\section{Carcinoma of the Kidney}

In 20 patients with carcinoma of the kidney $\left(\mathrm{T}_{1} \mathrm{~N}_{0} \mathrm{M}_{0}-\mathrm{T}_{2} \mathrm{~N}_{0} \mathrm{M}_{0}\right)$ hyperexcretion of NEC occurred in 5 and of TC in 11 (NEC range 0.8-15.2, median 2.2; TC range 0.9-30.4, median 3.2). In advanced clinical stages of the disease $\left(\mathrm{T}_{1} \mathrm{~N}_{1} \mathrm{M}_{0}-\right.$ $\mathrm{T}_{4} \mathrm{~N}_{4} \mathrm{M}_{1 \mathrm{~d}}$ ) elevated values of NEC were detected in 11 and of TC in 14 of the 25 patients investigated (NEC range 0.7-64.3, median 1.8; TC range $0.7-$ 124.4, median 4.4). Single values of these patients are illustrated in Fig. 1.

\section{Carcinoma of the Breast}

From 22 patients with cancer stage I-II, 5 showed slightly elevated values of NEC and 3 of TC, which could be observed in 21 and 19 , respectively, of the 70 patients with clinical stage III-IV (NEC range $0.6-$ 11.8, median 1.8; TC range 0.7-17.8, median 2.2). Single values are demonstrated in Fig. 2.

\section{Carcinoma of the Uterus}

From the 57 patients with carcinoma of the cervix 19 revealed elevated levels of NEC and 17 of TC (NEC range 0.6-19.6, median 1.8; TC range 0.7-35.4, median 2.2). 


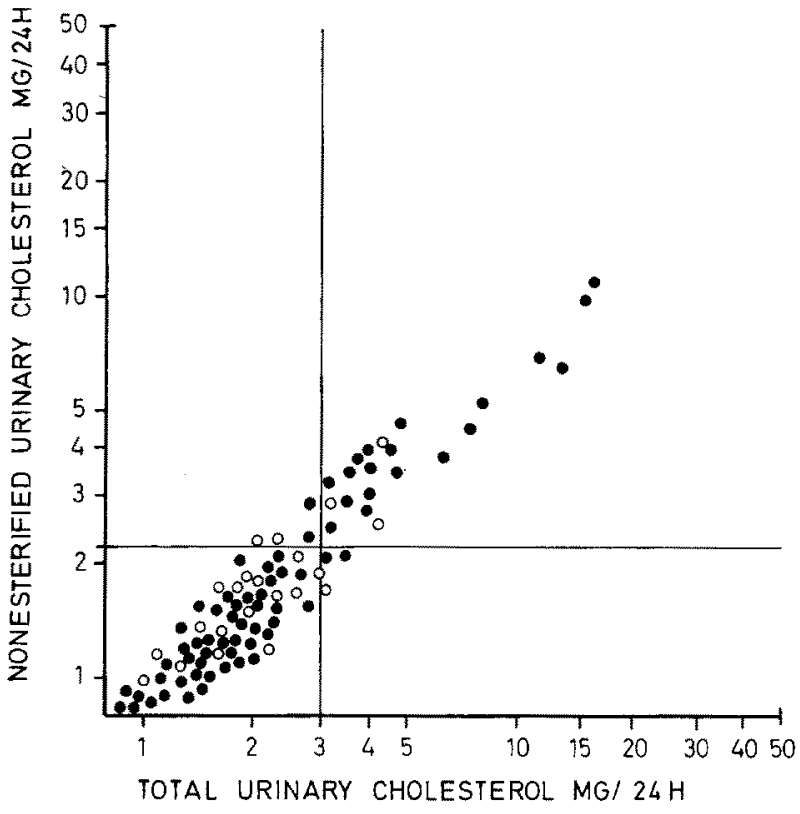

Fig. 2. Nonesterified and total urinary cholesterol in 91 patients with carcinoma of the breast. O stage I-II, - stage III-IV

In 40 patients with carcinoma of the corpus uteri hyperexcretion of NEC occurred in 13 and of TC in 11 (NEC range $0.8-13.2$, median 1.9 ; TC range 0.9-27.3, median 2.1). The individual results are illustrated in Fig. 3 and Fig. 4.

\section{Carcinoma of the Ovary}

6 out of 19 patients with carcinoma of the ovary revealed slightly elevated NEC or TC levels (NEC range 0.4-4.8, median 1.7; TC range 0.6-8.2, median 2.4).

\section{Carcinoma of the Testes}

In 21 patients with malignant diseases of the testes moderate hyperexcretion of NEC was observed in 5 and of TC in 6 patients (NEC range $0.4-3.8$, median 1.8 ; TC range $0.5-12.4$, median 2.3 ).

\section{Other Malignant Diseases}

The 16 patients with carcinoma of the bronchial tract showed normal urinary cholesterol values. 4 out of 28 patients with neoplasms of the gastrointestinal tract revealed slightly elevated levels of NEC and TC. In the 46 patients with malignant systemic diseases, hyperexcretion of NEC occurred in 7 and of TC in 9 cases (Fig. 5).

\section{Diseases of the Kidney and Urinary Tract}

In 47 patients with glomerular, tubular or vascular diseases of the kidney hyperexcretion of NEC took place in 12 and of TC in 20 (NEC range 0.5-6.6,

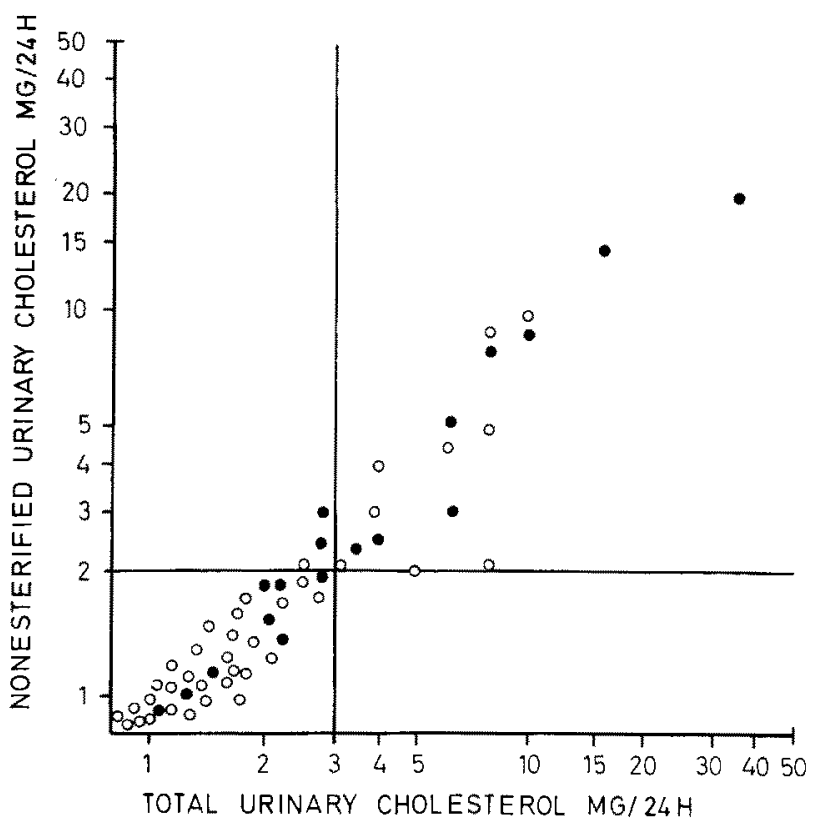

Fig. 3. Nonesterified and total urinary cholesterol in 57 patients with carcinoma of the cervix uteri. O stage I-II, - stage III-IV

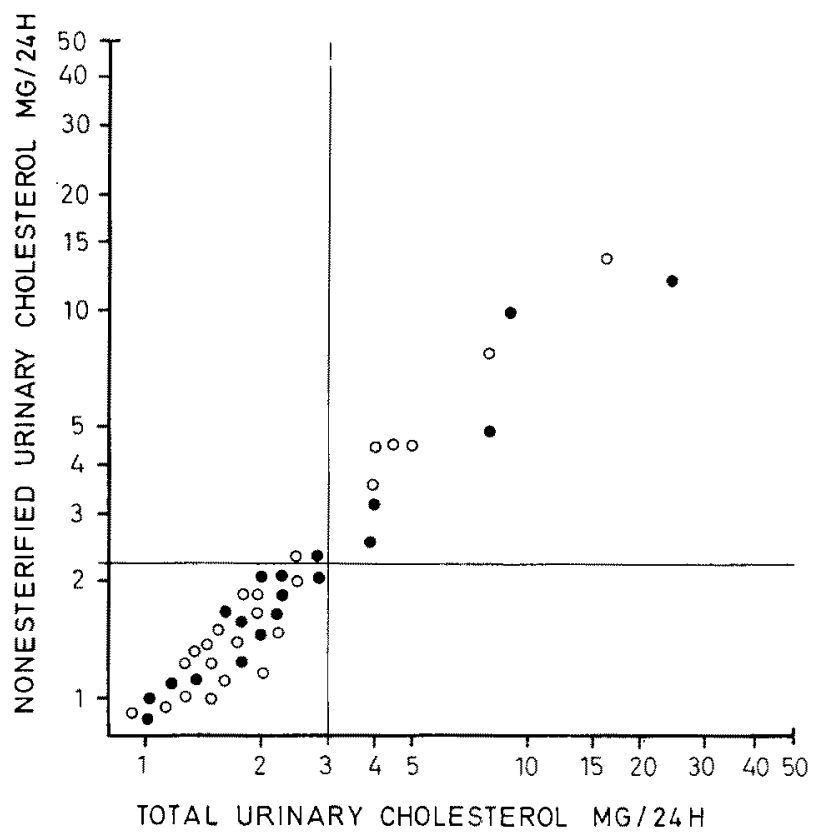

Fig. 4. Nonesterified and total urinary cholesterol in 40 patients with carcinoma of the corpus uteri. O stage I-II, $\bullet$ stage III-IV

median 1.8; TC range 0.6-11.5, median 2.8) (Fig. 6).

From the 29 patients with urolithiasis 8 revealed elevated levels of NEC and 13 of TC, similar findings were obtained in 29 patients with renal insufficiency of unknown etiology (NEC range 0.3-9.8, median 1.5; TC range 0.4-31.5, median 2.6) (Fig. 7).

In 27 patients with the nephrotic syndrome hyperexcretion of NEC was detected in 20 and of TC in 

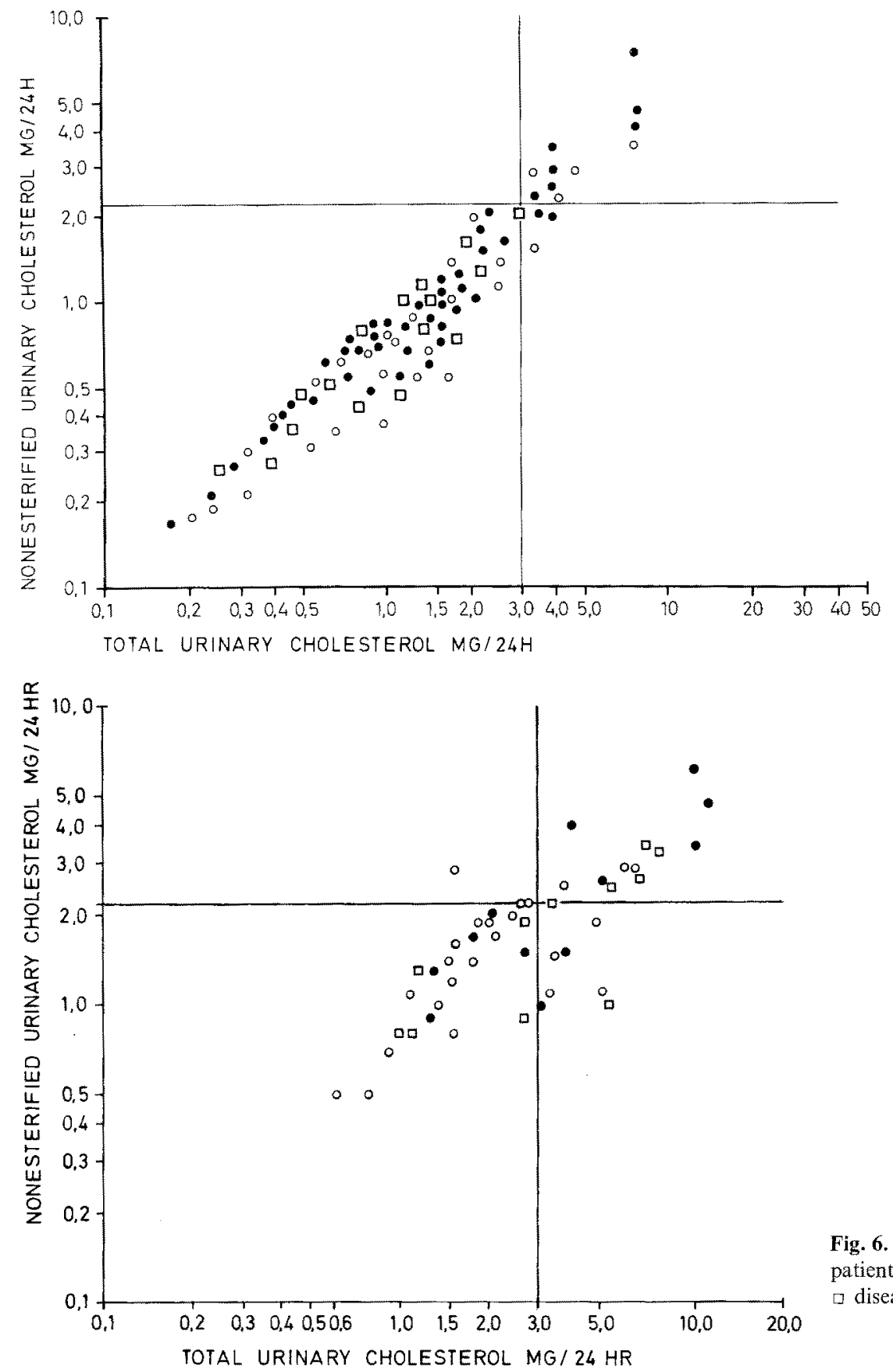

Fig. 5. Nonesterified and total urinary cholesterol in 16 patients with carcinoma of the bronchial tract $\square, 28$ patients with carcinoma of the gastrointestinal tract $O$ and 46 patients with malignant systemic diseases
Fig. 6. Nonesterified and total urinary cholesterol in patients with glomerular $\bullet$, tubular $O$ and vascular $\square$ diseases of the kidney
25 (NEC range $0.8-38.2$, median 4.4 ; TC range 1.0 93.5, median 12.6). Lower values of excretion were measured in 15 patients with renal cysts (NEC range 0.8-68.4, median 1.7; TC range 1.3-82.4, median 3.5) (Fig. 8).

32 patients with common infections of the urinary tract revealed normal urinary cholesterol excretion in all cases.

\section{Benign Prostatic Hyperplasia with Residual Urine}

The results obtained in the study of patients with prostatic hyperplasia and residual urine have been published in detail before, hyperexcretion of NEC was observed in 24 and of TC in 37 out of 57 patients (NEC range 0.3-49.0, median 2.0; TC range 0.4 112.3, median 5.8).

\section{Discussion}

Our results demonstrated pathologic values in prostatic carcinoma $T_{1} \mathrm{~N}_{0} \mathrm{M}_{0}-\mathrm{T}_{2} \mathrm{~N}_{0} \mathrm{M}_{0}$ in $37 \%$ of $\mathrm{NEC}$ and $45 \%$ of TC. In advanced clinical stages percentage of elevated values increased to $62.5 \%$ for NEC and $67.5 \%$ for TC. 


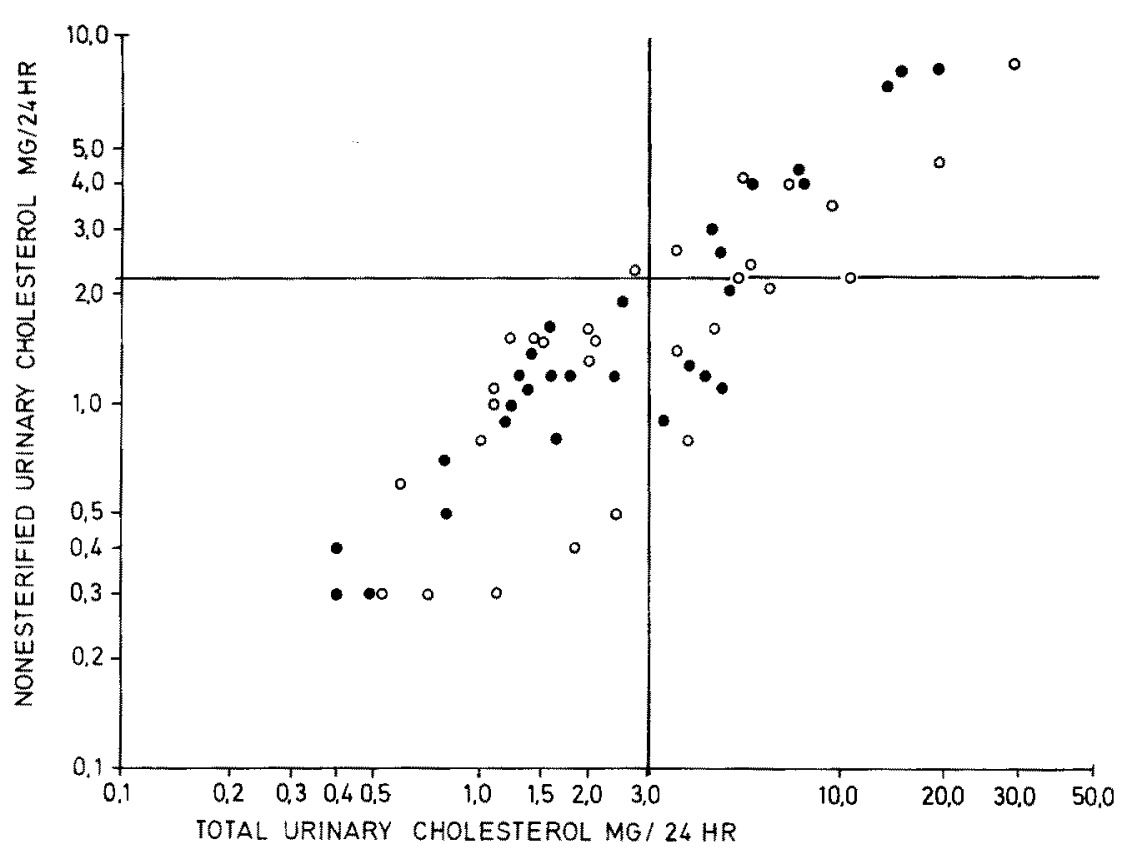

Fig. 7. Nonesterified and total urinary cholesterol in patients with urolithiasis - and renal insufficiency of unknown etiologyo

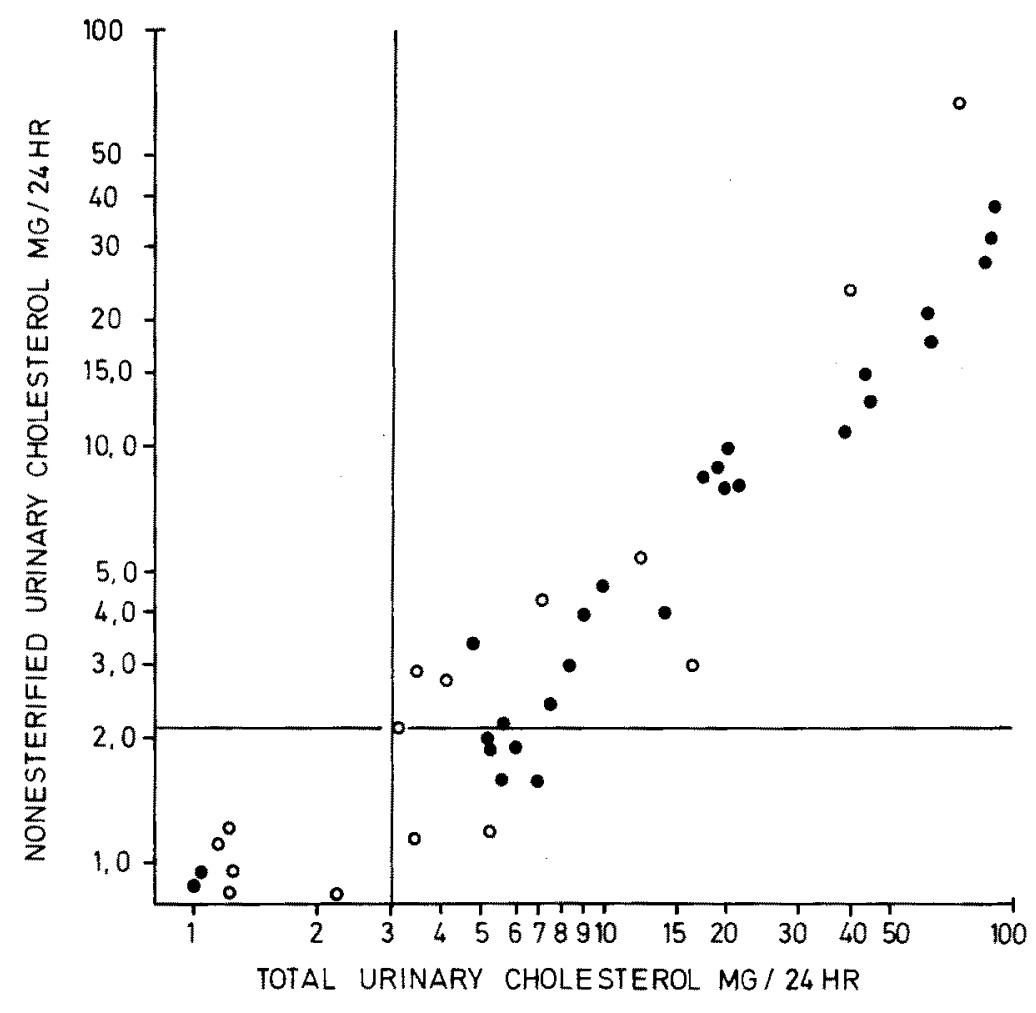

Fig. 8. Nonesterified and total urinary cholesterol in patients with nephrotic syndrome $\bullet$ and renal cysts 0

These findings are in good agreement with those reported recently (Belis and Cenedella 1979). In papilloma of the bladder NEC hyperexcretion was present in $56 \%$, elevated levels of TC were determined in $68 \%$, similar to data obtained in early stages of carcinoma of the bladder. In advanced clinical stages hyperexcretion of NEC was observed in $76 \%$ and of TC in $90 \%$. In early clinical stages of carcinoma of the kidney hyperexcretion of NEC was present in about $25 \%$ and of TC in about $55 \%$. Percentage of elevated values increased to 44 of NEC and 56 of TC in further advanced stages. In patients with carcinoma of the cervix or corpus uteri elevated levels of NEC or TC were detected in approximately $30 \%$, comparable to the results of previous studies (Acevedo et al. 1971; Acevedo et al. 1975). In early clinical stages of patients with breast cancer, marked hyperexcretion of urinary cholesterol has not been detected 
in contrast to patients with metastases. Malignant diseases of testes and ovary revealed moderate hyperexcretion of urinary cholesterol in $24-31 \%$, in carcinomas of other origin slightly elevated urinary cholesterol has been observed in about $12 \%$.

In view of these results it is concluded that the determination of especially total cholesterol in urine has a considerable diagnostic sensitivity for carcinomas of the urogenital system. It is more pronounced in patients with cancer of the kidney, prostate and bladder than uterus, ovary and testis.

However, urinary cholesterol hyperexcretion could not be considered to be a specific sign of urogenital malignancies. Findings also demonstrate elevated values in patients with prostatic adenoma and residual urine. In addition, hyperexcretion of urinary cholesterol is a common finding in kidney diseases, irrespective of etiology or any other clinical features. However, it is important to note that common infections of the urinary tract are not associated with hyperexcretion of urinary cholesterol.

Discussing the clinical value of the method presented one can state that increments of urinary cholesterol are not a specific sign of urogenital malignancies but are usually caused by malignant or nonmalignant diseases of the urogenital system.

The application of this method as a possible screening test in cancer detection programs seemed to be limited only little by lacking specificity or expensive methodology. In our opinion most important is the fact of low prevalence of urogenital carcinomas in unselected populations which would lead to low predictive values for a positive urinary cholesterol test and the presence of urogenital malignancies. This does not necessarily exclude the possibility that the urinary cholesterol method could be successfully applied in preselected populations with increased prevalence of urogenital carcinomas.

Although the physiologic mechanisms of urinary cholesterol excretion are not known, an excretion as a protein bound complex was suggested on the basis of ultrafiltration studies (Acevedo et al. 1970).

Enhanced production of lipoproteins by the malignant cells had been discussed to cause hyperexcretion of urinary cholesterol in cancer of steroid hormone producing glands or their main target tissues (Acevedo et al. 1973). In addition the presence of immuncomplex nephritis, a well known disease in cancer patients, could be responsible partially for elevated urinary cholesterol values (Kerkhoven et al. 1973; Sutherland and Mardiney 1973; Eagen and Lewis 1977).

However, in our opinion it is most likely that alterations of the urothelial cell membranes with subsequent loss of lipoproteins are responsible for hyperexcretion of urinary cholesterol irrespective of the underlying disease. Only in patients with the nephrotic syndrome seems the positive correlation between urinary protein and urinary cholesterol to support the suggestions that enhanced filtration of plasma lipoproteins, especially the HDL-fraction, is responsible for increased lipiduria (Klahr et al. 1967; de Mendoza et al. 1976; Bing and Starup 1935).

\section{References}

Acevedo HF, Campbell EA (1970) Urinary cholesterol III. Its excretion as a protein bound complex. Steroids 16:569-577

Acevedo HF, Campbell EA, Hayeslip, DW, Gilmore J, Merkow LP, Frich JC, Jr, Grauer RC (1971) Urinary cholesterol IV. Its excretion in women with neoplasms of the genital system. Obstet Gynec 37: 425-436

Acevedo HF, Campbell EA, Saier EL, Frich JC, Ir, Merkow LP, Hayeslip DW, Bartok SP, Grauer RC, Hamilton JL (1973) Urinary cholesterol $\mathrm{V}$. Its excretion in men with testicular and prostatic neoplasms. Cancer 32:196-205

Acevedo HF, Campbell EA, Frich JC, Jr, Dugan PJ, Saier EL, Merkow LP (1974) Urinary cholesterol VI. Its excretion in women with inoperable inllammatory carcinoma of the breast. Cancer $34: 1727-1736$

Acevedo HF, Campbell EA, Frich JC, Jr, Merkow LP, Hayeslip D, Gilmore J (1975) Urinary cholesterol VII. The significance of the excretion of nonesterified cholesterol in patients with uterine carcinomas. Cancer 36:1459-1469

Acevedo HF, Campbell EA, Frich JC, Jr, Hayeslip DW, Gilmore $J$ (1976) Urinary cholesterol VIII. Its excretion in women with ovarian neoplasms. Cancer 37:2847-2857

Belis JA, Cenedella RJ (1979) Urinary nonesterified cholesterol excretion in adenocarcinoma of the prostate. Cancer $43: 1840$ 1846

Bing J, Starup U (1935) Investigations of hyperlipemia and cholesterinuria. Acta Med Scand $86: 12-21$

Bloch E, Sobotka H (1938) Urinary cholesterol in cancer. I Biol Chem 124:567-572

Bruger M, Ehrlich SB (1943) Cholesterol content of the urine in patients with cancer. Arch Intern Med 72:108-114

Bruger M (1935) Cholesteroluria in Bright's disease. Am J Clin Pathol 5:504-515

Burchell MM, Earle JHO, Maclagan NF (1949) Urinary cholesterol in cancer: Urinary cholesterol excretion in cancer patients and control subjects. Br J Cancer 3:42-51

Burchell MM, Maclagan NF (1949) Urinary cholesterol in cancer: Chemical state of urinary cholesterol and methods of estimation. Br J Cancer 3:52-61

Chu TM, Shukla SK, Mittelman A, Murphy GP (1975) Comparative evaluation of serum acid phosphatase, urinary cholesterol and androgens in diagnosis of prostatic cancer. Urology $6: 291$ 294

Comings DE (1963) Anisotropic lipids and urinary cholesterol excretion. JAMA 183:128-133

Eagen JW, Lewis EJ (1977) Glomerulopathies of neoplasia. Kidney Int 11:297-306

Frick J, Spiteller G (1968) Cholesterin und Hamtrakterkrankungen. Z Urol $61: 833-838$

Jüngst D, Pickel A, Marx FJ, Elsässer E, Karl HJ (1979a) Urinary cholesterol excretion in men with benign prostatic hyperplasia and carcinoma of the prostate. Cancer $43: 361-367$

Jüngst D, Pickel A, Stadler A, Marx FJ, Elsässer E, Karl HJ (1979b) Comparative evaluation of nonesterified and total urinary cholesterol in papilloma and carcinoma of the bladder. Cancer $43: 2486-2491$ 
Kerkhoven P, Briner J, Blumberg A (1973) Nephrotisches Syndrom als Erstmanifestation maligner Lymphome. Schweiz Med Wochenschr 103:1706-1709

Klahr S, Tripathy K., Bolanos O (1967) Qualitative and quantitative analysis of urinary lipids in the nephrotic syndrome. J Clin Invest 16:1475-1481

de Mendoza SG, Kashyap ML, Chen CY, Lutmer RF (1976) High density lipoproteinuria in nephrotic syndrome. Metabolism 25:1143-1149

Sobotka H, Bloch E (1939) Urinary extractives in cancer. Am J Cancer $35: 50-54$

Sobotka H, Bloch E, Rosenbloom AB (1940) Urinary cholesterol in cancer II. Am J Cancer 38:253-256

Spiteller-Friedmann M, Spiteller G, Spiteller H, Frick J (1971) Zur Frage der Ausscheidung von Cholesterin im Harn bei verschiedenen Erkrankungen (vornehmlich bei Tumorerkrankungen des Urogenitaltrakts). Österr Z Krebsforsch 5:25-35

Sutherland JC, Mardiney MR (1973) Immuncomplex disease in the kidneys of lymphoma-leukemia patients. The presence of an oncornavirus-related antigen. J Natl Cancer Inst 50:633-644
Trappe W (1942) über den Cholesteringehalt des Harns von Geschwulstkranken. Z Krebsforsch 53:47-56

Vela BA, Acevedo HF (1969) Determination of urinary cholesterol by gas-liquid chromatography. Steroids 14:499-517

Zimmer JG, Dewey R, Waterhouse Ch, Terry R (1961) The origin and nature of anisotropic urinary lipids in the nephrotic syndrome. Ann Intern Med 54:205-214

Received August 29, 1980

Accepted December 28, 1980

Dr. D. Jüngst

Med. Klinik II

Klinikum Großhadern

Marchioninistr. 15

D-8000 München 70

Federal Republic of Germany 